\title{
Measuring the Haptic Perception of Leather Surfaces
}

\author{
Björn Falk ${ }^{1}$, Annika Neumann ${ }^{1 \mathrm{a}}$, Andrea Stoll ${ }^{2}$ and Robert Schmitt ${ }^{1}$ \\ ${ }^{1}$ Chair of Production Metrology and Quality Management, Laboratory for Machine Tools and Production Engineering \\ (WZL) \\ ${ }^{2}$ Research Institute of Leather and Plastic Sheeting (FILK), Freiberg/Saxony
}

\begin{abstract}
Products on today's markets are technically mature. A differentiation by conventional criteria is increasingly difficult or even impossible for the customers. Subjectively influenced factors replace clearly defined technical attributes as criteria for differentiation. Therefore it is necessary for manufacturers to identify those product characteristics which are perceived by the customers and influence their quality rating. This paper presents a sensory method to detect the customers' haptic evaluation and rating of leather and artificial leather surfaces. These customer requirements and ratings can systematically be linked to measurable technical parameters and communicated and controlled during the product development process.
\end{abstract}

Résumé. Aujourd'hui les produits sur les marchés sont techniquement muris. Une différenciation selon les critères classiques est de plus en plus difficile et presque impossible pour les clients. Facteurs influencés subjectivement remplacent les attributs techniques bien définis, comme des critères de différenciation. Pour cette raison c'est nécessaire pour les manufacturiers d'identifier les attributs des produits qui sont aperçus par les clients et d'influencer leur évaluation de qualité. Cette publication présente une méthode sensorielle pour la détection de l'évaluation haptique et l'estimation des superficies en cuir et en cuir synthétique. Ces besoins des consommateurs et évaluations peuvent être combinés systématiquement en des paramètres techniques mesurables et peuvent être communiqués et contrôlés pendant le procès de développement du produit.

\section{Perceived Quality}

The term quality is defined as the degree to which a set of inherent characteristics fulfils requirements. [1] This term is used to describe characteristics of a material object, as a consumer good or intangibles. On the other hand quality is used as an evaluative attribute in terms of the usability and goodness of the observed object or as a value-neutral description of its condition. [2] In particular perceived quality is defined as the result of a cognitive and emotional comparison process between customer's conscious and unconscious expectations regarding criteria like price, design, brand image or product experiences and the realised technical product features in specific situations of use $[3,4]$.

\subsection{Determination of Quality Perception}

In order to identify the factors that are relevant for evaluating the quality of a product, Schmitt et al. [3] developed a model that provides a structured approach to break the customer's overall impression down into single technical parameters. Customer perception is successively divided into five levels, as the following figure shows:

The approach presented in this paper is based on level three, four and five of the model (see Figure 1). The so called quality attributes form the third level and include the factors which can still be defined by the customer. The perception of the quality attributes is like the overall impression a subjective interpretation and needs further analysis.

This is done by splitting the quality attributes in one or more partly objectified descriptors that make up the fourth level of the model. Descriptors provide the link between the subjective quality attributes and the technical parameters that can be objectively measured with metrological methods and therefore be influenced in the production.

The fifth level consists of these technical parameters. They are the result of a complete objectification of a customer's perception and can only be quantified by metrological methods. The technical parameters are the levers in design and production in order to manipulate the customer's perception and evaluation of a certain product. [5]

\footnotetext{
${ }^{a}$ Corresponding author: a.neumann@wzl.rwth-aachen.de
} 
Figure 1. Entrepreneurial approach towards Perceived Quality [5]

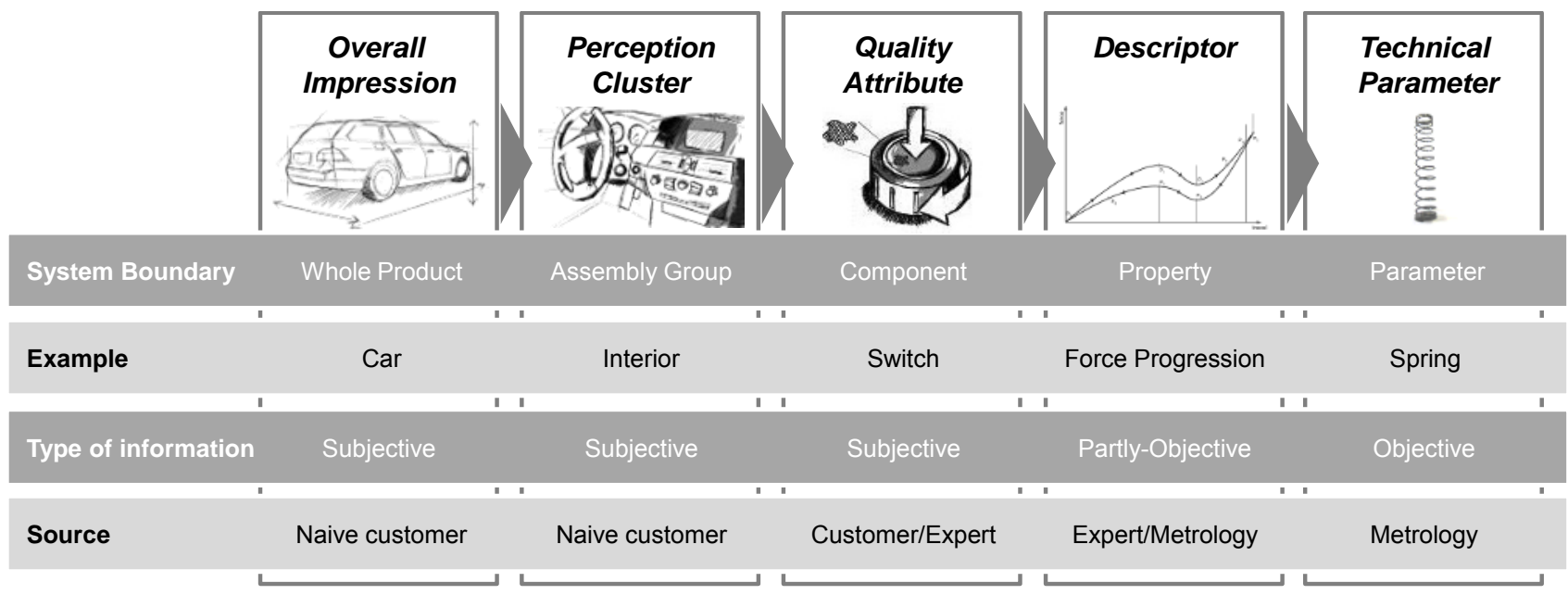

In order to give specific design recommendations for product development, a relationship between the subjective product rating by the customer and the objectively measured technical attributes must be established.[6] Therefore several questions have to be answered:

1. Which quality attributes and descriptors describe a product and influence the customer's rating?

2. Which measurable technical parameters define these descriptors?

3. How do customers perceive the descriptors of a specific product?

4. What are the thresholds?

5. Which values of these descriptors are preferred for a particular application by the customer?

To answer these questions the following procedure was developed:

1. Identification, selection and definition of relevant quality attributes und their descriptors in workshops.

2. Objective measurement of the products' technical parameters.

3. Sensory evaluation of several products based on the predefined descriptors: Humans as a measuring device.

4. Determination of perception thresholds for relevant descriptors, by changing gradually the surface characteristics and analysing the perception of the manipulated surfaces.

5. Collection of preference data with hedonic tests and correlation with data from explorative tests.

The study presented below aims to answer the questions 1 to 4 by providing an exemplary approach from level three to five of the model (see Figure 1), within the case of the haptic evaluation of leather and artificial leather surfaces. It creates the basis for answering the five open questions in a further study in order to give concrete design recommendations for product development.

\section{Case Study of Leather Surfaces}

In the present project the Research Institute of Leather and Plastic Sheeting (FILK), Freiberg/Saxony and the Chair of Production Metrology and Quality Management, Laboratory for Machine Tools and Production Engineering (WZL) at the RWTH Aachen University developed and optimized a method that compares a product's objectively measurable technical parameters with its subjective evaluation and rating based on human perception. This study was focussed on leather and artificial leather surfaces. The thereby developed methodology can subsequently be transferred to specify other kinds of surfaces (e.g. textiles). The determination of the human evaluations and ratings was carried out by using scientific methods from the fields of empirical social research, sensory science and product research. The technical measurement of specific product characteristics, which had to be identified, was a further challenge of the present research project. The compiled results will be used for quality evaluation and anticipation of possible human sensations, in order to ensure a customer-oriented and resource-efficient product development.[6]

\subsection{General Methodology}

The selection of materials was carried out in cooperation with leather and artificial leather manufacturers and the automotive industry. All possibilities from current standard materials to highpriced special materials were provided. By influencing their microstructure in the production process, materials that differed in lamination, grain, colour and surface could be provided. In total 98 surface variants were selected and analysed. Thereby over 2000 technical parameters were determined by material properties and measurement. Several studies were conducted in order to answer the open questions of the research project. The materials were clamped on demonstrators (see Figure 2) especially designed and constructed for this research project. 
Figure 2. Demonstrator for sensory studies

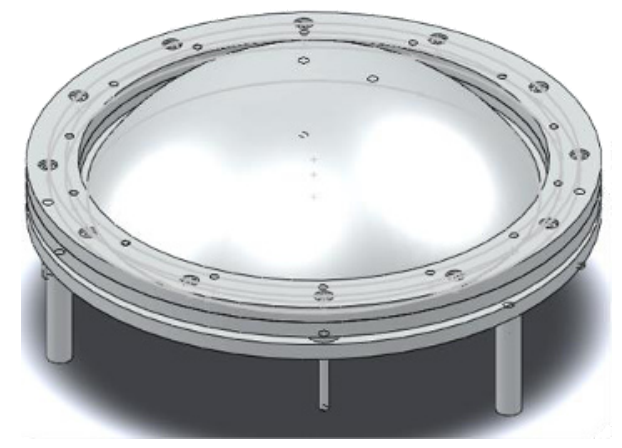

The surfaces were analytically evaluated in the first study by about 600 subjects in two sensory tests. In these test the subjects stated both their perception of the surfaces' characteristics as well as their personal hedonic overall quality impression on a scale from 1-10.

The descriptors used for the analytical evaluation and the hedonic rating of the selected surfaces were previously identified, selected and defined in two workshops with 12 "naive" subjects each. During these workshops the selected parameters were categorized into 4 main groups:

1. Temperature sensation

2. Friction characteristics

3. Deformation

4. Surface / topography

All materials have been analysed with different measuring devices. In order to receive comparable results, during the workshops the human tactile parameters, like force and velocity, were accurately determined and transferred to the measuring devices.

The second study was necessary to verify the results of the first study. With the purpose to check the transferability of the developed approach and thus the collected descriptors on other materials a third study was carried out with six different textiles.

In order to confirm the results with real components an additional smaller study was conducted with 100 subjects evaluating four different leather and artificial leathers, already used in the previous studies, on automotive armrests.

\subsection{Results}

In the workshop 13 descriptors for the evaluation and rating of leather and artificial leather surfaces could be identified: temperature sensation, hardness, density of structure, regularity in structure, differences in structure according to orientation, edges in structure, plainness, roughness, adherence, memory effect, slipperiness, stretch ability and temperature development. Naturalness, quality impression, sense and connotation are four hedonic descriptors which have been defined in advance.

Using pressure measuring films, the human tactile parameters were accurately determined and transferred to the measuring devices. In average, humans touched the surfaces with a
- force of $6,65 \mathrm{~N}$ (static) / 2,35N (dynamic) and a

- velocity of $77.5 \mathrm{~mm} / \mathrm{s}$.

Out of the comprehensive amount of data selected results are presented:

The correlation between single evaluation of each descriptor and the overall rating of the surfaces was analysed with the help of Cramer's V. The descriptors: quality impression, naturalness and roughness showed the strongest relations with values above 0.3 [7].

Concerning the descriptor "sense" the following statements can be made:

- Hard and rough materials are perceived to be very unpleasant

- $2 / 3$ of the subjects rate smoother and softer materials as more pleasant

- No tendency for slipperiness

Roughness and hardness are equivalent and have significant effect on the sensation!

The highest coefficients of correlation between the subjective descriptor evaluation and objectively measured technical parameters were achieved for the roughness parameters $R_{a}$ and $R_{z}(\max .0 .74)$ with several descriptors.

By factor analysis five factors could be identified that cause the evaluation of 14 descriptors:

1. Topography: roughness, density of structure, edges in structure, plainness

2. Pliability: hardness, stretch ability, slipperiness

3. Heterogeneity in structure: regularity in structure, differences in structure according to orientation

4. Surface inertia: adherence, memory effect

5. (Aesthetic: quality impression, sense, naturalness)

For the descriptors contact temperature, temperature development and connotation no causing factor could be found.

The regression analysis showed high coefficients of determination for the descriptors density of structure $\left(\mathrm{R}^{2}=0.514\right)$, plainness $\left(\mathrm{R}^{2}=0.42\right)$, roughness $\left(\mathrm{R}^{2}=0.397\right)$, hardness $\left(\mathrm{R}^{2}=0.338\right)$ and edges in structure $\left(\mathrm{R}^{2}=0.33\right)$ and their set of technical parameters.

For the sensations hardness, roughness, structure, density, texture, edges and flatness linear relationships with relevant characteristic parameters could be collated in type and proportion with medium to large correlation. The remaining descriptors showed only minor correlation.

With the help of paired comparison of all descriptors concrete perception thresholds could be determined. $75 \%$ of the subjects were able to distinguish between surfaces with a difference in:

- Roughness: $\Delta \mathrm{Ra}>4 \mu \mathrm{m}$

- Deformation: $\Delta \mathrm{F}>300 \mathrm{mN}$

- Slipperiness: $\Delta \mathrm{FR}, \mathrm{G}>200 \mathrm{mN}$

- Contact temperature: $\Delta \mathrm{T}>1,25$ Sensotact scale parts (scale: 1-100)

The technical parameters such as roughness and hardness of the materials change with their processing in 
an unpredictable way. Therefore it is recommended to determine the parameters while clamped on the demonstrators that are used in the sensory studies.

Since the identical surfaces were evaluated significantly accurate, the results showed a high reliability (see Figure 3). The descriptors of the same surface have been evaluated by the subjects with an average difference of 0.45 to 0.8 in two different studies. Depending on the surface, the maximum difference for one descriptor's average value varied from 1.25 and 1.64 on scale of 10. [6]

Figure 3. Accuracy of repetitive investigations

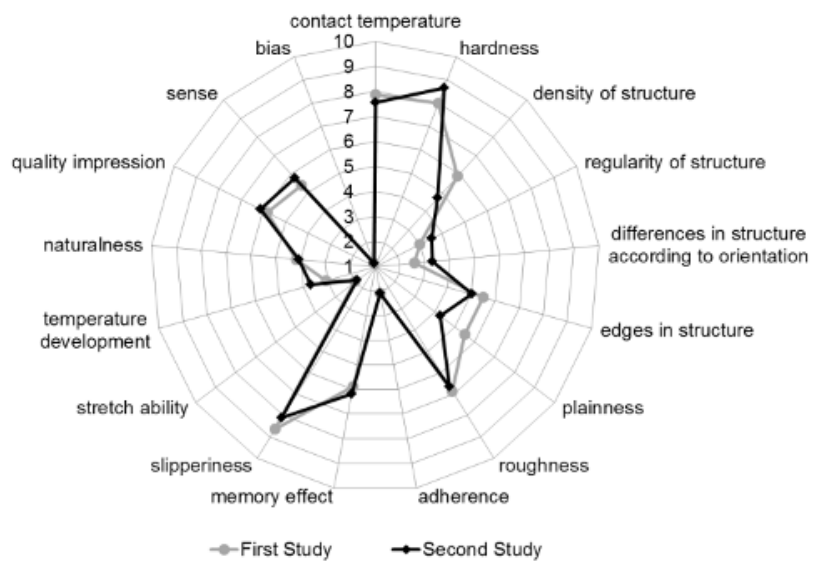

Thus, the objective to develop a method for comparing human and metrological parameters, the verification of this method for other materials and the determination of perception thresholds has been achieved. Nevertheless, the method needs to be further improved. In particular regarding the preparation of a link between a subject's hedonic quality judgment and the perceived product properties.

\subsection{Discussion and Outlook}

All in all the results achieved in this research project represent a progress for the objectification of subjective surface descriptions. Besides the investigated and repeatedly tested measurement methods for the determination of subjective evaluations of leather and artificial leather surfaces could be standardized as well.

The various subjective sensory studies showed a high repeatability in terms of the subjects' evaluations (see Figure 3). The evaluations of trained subjects showed a higher accuracy than those of the naive subjects. Each subjective description of a surface could be assigned to one or more objectively measured technical parameters. For several descriptors a correlation between the objectively measured technical parameters and the subjects' evaluation was found.

But there were significant differences for both the measured technical parameters as well as for the subjective surface descriptions when comparing the clamped and unclamped materials. Nevertheless, it has been possible to determine perception thresholds of 4 descriptors for the unclamped materials. Hence, there is still potential in the evaluation of the surfaces in terms of the remaining descriptors.

In the sensory tests of the first study the subject's perception of certain product attributes was asked via 13 analytical descriptors as well as his or her personal overall quality impression via four hedonic descriptors. Thereby human perception and the personal ratings of the subjects could be detected for each surface. A detailed rating whether the value of a certain descriptor is suitable for a specific situation of use has not been queried in the presented study. Thus it was not possible to adequately connect the value of certain technical parameters with the subjects' quality rating. Thus, the descriptive content is not sufficient to derive concrete recommendations for product design and production.

To have a better understanding of the customers' perception, a correlation of the technical parameter and the customer rating is necessary. Based on the results of the presented research project, an exemplary approach has been developed. This connects the value of a product's technical parameters with the customers' ratings for a specific application in three steps (see Figure 4).

Figure 4. Establishment of a connection between customer rating and technical parameters

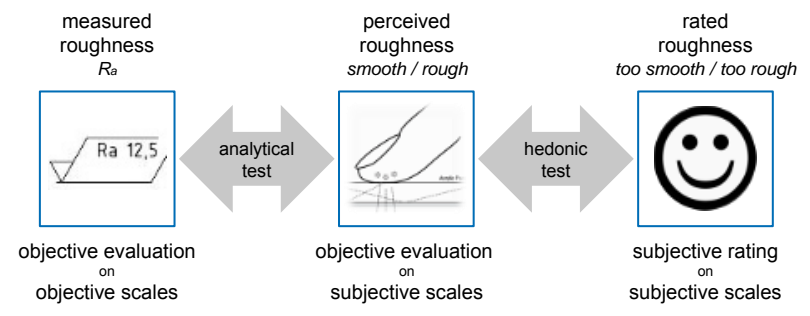

Objectives need to be selected according to quality attributes and their descriptors. These will be initially identified and reduced to a reasonable number of 5-10 descriptors in so-called expert workshops by at least 12 product-specific trained experts [8, 9]. With these descriptors, a questionnaire will be designed and tested in a pre-test with at least 20-50 subjects [10].

In order to derive recommendations for the product development, those values of technical parameters must be identified, which are perceived by the customers and rated to be optimal for a particular application.

The sensory study needs to be structured in two parts: the analytical evaluation and the hedonic rating. Each descriptor needs to be evaluated analytically and rated hedonically. This is necessary to have a connection between the metrological detectable and objective values of technical parameters and the customer's subjective general haptic impression.

The objective measurement of the examined materials' technical parameters must be carried out in the same installation as used in the sensory evaluation and rating by the subjects. For the present research project this means that the materials need to be clamped on the demonstrators for both the objective measurement, as well as the sensory tests. This secures that the derived connection reflects reality. Human perception is captured in an analytical sensory study. The subjects will range the 
materials according to their perceived descriptor values. Therefore reference samples, which show the minimum and maximum value of each descriptor, can be provided.

In order to create a connection between the semiobjective human perception of a certain descriptor and how this descriptor is hedonically rated by the subjects, the personal preference is queried in a hedonic study for each descriptor for a particular application. Therefor a "Just About Right"-scale was chosen. On such a JARscale the subjects rate whether a descriptor's value is "too strong", "just about right" or "too weak" (further subdivisions possible). With the obtained data, values for technical parameters of each descriptor will be specified which are perceived as optimal. [11, 12] In order to facilitate the link of the results from analytical evaluation and hedonic rating, a JAR-scale with one scale point more than the scale used for the analytical evaluation should be used (e.g. a 6-point-scale for the analytical test and a 7-point JAR-scale for the hedonic test).

With the gained knowledge costs from overengineering that is not valued by the customers can be avoided and their quality perception can be manipulated. For the presented research project, this can be implemented through a targeted design of surfaces and their microstructures.

\subsection{Conclusion}

The adapted method is a possibility for companies to derive structured information on different levels of interest and abstraction. The presented study of leather surfaces only shows one excerpt. The presented method is a step forward to objectify human haptic and sensory perception and to correlate them with technical parameters. The developed method has to be tested and optimized in a further research project.

\section{Acknowledgment}

The descriptive analysis and measurement of leather surfaces, which is mentioned in this work, is funded with budget funds of the Federal Ministries of Economics and Technology (BMWi) via the German Federation of Industrial Research Associations „Otto von Guericke e.V." (AiF) (IGF-Nr.: 16134 BG/2) and supported by the Development Association of the Research Institute for Leather and Artificial Leather (FILK).

\section{References}

1. DIN EN ISO 9000, Quality management systems Fundament als and vocabulary, 18 (2005)

2. I. Barofsky, Quality: Its Definition and Measurement As Applied to the Medically Ill, 10 (2012)

3. R. Schmitt, B. Quattelbaum, H. Lieb, Perceived Quality as a key factor for strategic change in product development, IEEE International Engineering Management Conference, 311-316 (2008)

4. R. Schmitt, T. Pfeifer, Qualitätsmanagement: Strategien - Methoden - Techniken, 4, 219-222 (2010)

5. R. Schmitt, B. Falk, B. Quattelbaum, Product Quality from the Customers' Perspective: Systematic Elicitation and Deployment of Perceived Quality Information, Proceedings of the 6th CIRPSponsored International Conference on Digital Enterprise Technology, 211-222 (2009)

6. B. Falk, A. Neumann, R. Schmitt, Correlation Between Perceived Quality Characteristics and Measured Technical Parameters for Leather Surfaces, Proceedings of $11^{\text {th }}$ International Symposium on Measurement Technology and Intelligent Instruments (ISMTII 2013), CD 21-02 (2013)

7. N. J. Salkind, Encyclopedia of Research Design, 1, 410 (2010)

8. Norm DIN 10967-2, Sensorische Prüfverfahren Profilprüfung Teil 2: Konsensprofil, 3 (2000)

9. D. Plaul and K. Schüssler, Deskriptive Prüfungen: Profilprüfungen - Konsensprofil, Praxishandbuch Sensorik in der Produktentwicklung und Qualitätssicherung, 16, chapter 2.32 (2007)

10. D. Paier, Quantitative Sozialforschung: Eine Einführung, 120-121 (2010)

11. H. R. Moskowitz, J. H. Beckley, A. V. A. Resurreccion, Sensory and Consumer Research in Food Product Design and Development, 2, 189-192 (2012)

12. E. Chambers, M. B. Wolf, Sensory Testing Methods, ASTM manual series MNL, 2, 50-52 (1996) 